\title{
Corpos e territórios negros:
}

\section{representacỗes da religiosidade afro-brasileira}

no documentário Orí (1989)*

Ceiça Ferreira**

Este artigo tem como objetivo principal analisar as representações da religiosidade afro-brasileira do documentário Orí (1989), dirigido pela cineasta Raquel Gerber, com narração e textos da historiadora Beatriz Nascimento, situando-o no contexto da produção cinematográfica nacional. A partir dos estudos culturais, do pensamento negro brasileiro e da metodologia de análise fílmica, investiga-se a construção narrativa e estética desse filme, que tem como ideia central a pesquisa de Beatriz Nascimento sobre o quilombo, suas origens africanas, sua continuidade histórica no Brasil no período colonial e sua ressignificação nos anos de 1970, quando passa a designar espacialidades como as escolas de samba, os bailes black, os movimentos negros e os terreiros de candomblé. Foi estudado como a religiosidade afro-brasileira tem um papel central nesses territórios negros, nos quais se dá a reconstrução das identidades negras, a tomada de consciência por meio do orí, palavra de origem iorubá, que significa "fazer a cabeça" fazer o rito de iniciação no candomblé, ou seja, uma possibilidade de renascimento. Conclui-se que tal documentário oferece representações da religiosidade afro-brasileira como um sistema de pensamento, que se inscreve na tessitura fílmica por meio da pluralidade de vozes, da centralidade visual de corpos negros em transe, das relações de pertencimento dentro do terreiro, e da ligação com a terra e com a ancestralidade.

Palavras-chave: Representação, documentário, religiosidade afro-brasileira, população negra, quilombo, territórios negros doi 10.11144/javeriana.mavae15-1.cetn

Recebido: 9 de junho de 2019

Aceito: 17 de julho de 2019

Disponible en línea: 1 de enero de 2020

* $\quad$ Artigo de investigação. Derivado de minha dissertação de mestrado Barravento, Orí e Santo Forte: representações das religiões afro-brasileiras no cinema, defendida em 2010.

** Graduada em Comunicação Social - Jornalismo e Mestre em Comunicação pela Universidade Federal de Goiás (UFG). Doutora em Comunicação pela Universidade de Brasília (UnB). Professora e pesquisadora da Universidade Estadual de Goiás (UEG). ORCID: 0000-0003-0625-6923 Correo electrónico: ceicaferreira@gmail.com

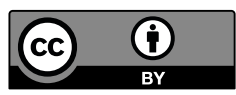




\section{Black Bodies and Territories: Representations of
Afro-Brazilian Religiosity in the
Documentary Orí(1989) Representations of
Afro-Brazilian Religiosity in the
Documentary Orí(1989) Representations of
Afro-Brazilian Religiosity in the
Documentary Orí(1989)}

This article aims to analyze the representations of Afro-Brazilian religiosity in the documentary Orí (1989), directed by filmmaker Raquel Gerber, with narration and texts by historian Beatriz Nascimento, placing it in the context of national film production. From cultural studies, the Brazilian black thought and the methodology of filmic analysis, the narrative and aesthetic construction of this film is investigated, having as its central idea Beatriz Nascimento's research on the quilombo, its African origins, its historical continuity in the film. Brazil in the colonial period and its reframing in the 1970s, when it came to designate spatialities such as samba schools, black balls, black movements and candomblé terreiros. It was studied how Afro-Brazilian religiosity plays a central role in these black territories, in which the reconstruction of black identities takes place, the awareness through the orí, word of Yoruba origin, which means "to make head," to do initiation rite in candomblé, that is, a possibility of rebirth. It is concluded that this documentary offers representations of Afro-Brazilian religiosity as a system of thought, which is inscribed in the filmic fabric through the plurality of voices, the visual centrality of black bodies in trance, the relations of belonging within the terreiro, and of the connection with land and ancestry.

Keywords: Representation, documentary, Afro-Brazilian religiosity, back population, quilombo, black territories

\section{Cuerpos y territorios negros: representaciones de la religiosidad afrobrasileña en el documental Orí(1989)}

Este artículo tiene como objetivo analizar las representaciones de la religiosidad afrobrasileña en el documental Orí(1989), dirigido por la cineasta Raquel Gerber, con narración y textos de la historiadora Beatriz Nascimento, situándolo en el contexto de la producción cinematográfica nacional. A partir de la teoría documental, los estudios culturales, el pensamiento negro brasileño y la metodología de análisis cinematográfico, investigamos la construcción narrativa y estética de esta película, que se centra en la investigación de Beatriz Nascimento sobre el quilombo, sus orígenes africanos, su continuidad histórica en Brasil en el período colonial y su resignificación en la década de 1970, cuando llegó a designar espacialidades como las escuelas de samba, los bailes negros, los movimientos negros y terreiros de candomblé. Se estudió cómo la religiosidad afrobrasileña desempeña un papel central en estos territorios negros, en los que tiene lugar la reconstrucción de las identidades negras, la conciencia a través del orí, palabra de origen yoruba que significa "hacer cabeza". rito de iniciación en candomblé, es decir, una posibilidad de renacimiento. Se concluye que este documental ofrece representaciones de la religiosidad afrobrasileña como un sistema de pensamiento, que se inscribe en el tejido fílmico a través de la pluralidad de voces, la centralidad visual de los cuerpos negros en trance, las relaciones de pertenencia dentro del terreiro, y de la conexión con la tierra y la ascendencia.

Palabras clave: Representación, documental, religiosidad afrobrasileña, población negra, quilombo, territorios negros 


\section{Cinema, identidades e relações de poder}

$>$ As representações veiculadas nos meios de comunicação e no cinema se configuram um poderoso mecanismo de manutenção dos regimes de visibilidade impostos à população negra e suas expressões culturais e religiosas no Brasil (Araújo 2000; Carrança e Borges 2004; Silva 2010, 2016). Por meio de imagens e conteúdos são difundidos significados, concepções e visões de mundo dominantes, que se correlacionam com os processos de exclusão vigentes na convivência inter-racial brasileira, ainda fortemente estruturada no sistema escravista/patriarcal, que perdurou oficialmente no país por mais de três séculos. Isso demonstra a dimensão política dos sistemas de representação e sua influência na construção das identidades e nos processos de subjetivação dos indivíduos, revelando assim a natureza discursiva dos fatos e fenômenos historicamente construídos.

devemos pensar as identidades sociais como construídas no interior da representação, através da cultura, não fora delas. Elas são o resultado de um processo de identificação que permite que nos posicionemos no interior das definições que os discursos culturais (exteriores) fornecem ou que nos subjetivemos (dentro deles). (Hall 1997, 8)

Nesse sentido, vale salientar a importância do cinema na reconfiguração da realidade, como aponta Luz (2002). Com base em sua capacidade de fabulação, o filme não conta apenas; ele mostra, reinventa o mundo e por isso o autor defende a necessidade de pensar quem detém o poder de criar essa representação do mundo. Logo, não é possível se desvincular o cinema da esfera da interlocução social e suas relações de poder, visto o papel significativo da produção cinematográfica brasileira na veiculação de um projeto de identidade nacional forjado pelas elites, no qual a população negra é excluída (Sodré 1999) ou visível apenas por meio de estereótipos.

Stuart Hall (2010) argumenta que a noção de estereótipo é fundamental para a representação da diferença racial, pois, como prática significante integrada à manutenção da ordem social e simbólica, ela é capaz de estabelecer fronteiras entre o "normal" e o "desviante", entre o "aceitável" e o "inaceitável", e assim permite excluir tudo o que não pertence, o que não se encaixa. Visões estereotipadas das religiões afro-brasileiras são recorrentes no cinema e também na televisão, pois "tiveram também pouco destaque nas novelas e, em algumas delas, sofreram referências negativas, associadas à ignorância ou ao mal", pontua Araújo $(2000,307)$.

Ainda sobre a produção televisiva, em janeiro de 2019, após 15 anos de uma ação judicial, a Rede Record (de propriedade do bispo Edir Macedo, fundador da Igreja Universal do Reino de Deus) foi condenada a exibir quatro programas sobre religiões de matriz africana como direito de resposta às representações 
ofensivas apresentadas pela emissora em sua programação no ano de 2004 (Jornal Gazeta do Povo 2019). Nesse sentido, ao discutir as representações ficcionais e documentais em torno das religiões afro-brasileiras, Guimarães (2019) ressalta o ponto de vista de lideranças políticas e religiosas das comunidades de terreiro, como Makota Valdina (do terreiro Nzo Onimboyá, de Salvador) e Pai Ricardo de Moura (da Casa de Caridade Pai Jacob do Oriente, de Belo Horizonte):

Makota Valdina denunciou o quanto fizeram mal ao povo de santo as imagens produzidas sobre os terreiros, pois várias delas desrespeitaram a humanidade dos seus integrantes e frequentadores. Até mesmo no caso das pesquisas antropológicas, as comunidades pouco se reconhecem na identidade que lhes é atribuída pelos pesquisadores, ela enfatizou. Pai Ricardo de Moura, por sua vez, mencionou a "gula daqueles que querem capturar as imagens do outro." Para ele, um dos maiores problemas reside no fato de que as imagens não conseguem apreender nem o saber nem o caminho percorrido para obtê-lo, realizado pelos que experimentam cotidianamente o axé em suas vidas. (Guimarães 2019, 25) ${ }^{1}$

A intolerância praticada contra as religiões afro-brasileiras é uma constante tanto na produção simbólica quanto no contexto social, especialmente nos últimos anos com a ascensão de grupos religiosos neopentecostais como maioria na política nacional e mais recentemente com a eleição de um candidato de extrema direita para presidência da república. Esse avanço de posturas conservadoras tem incitado a discriminação contra adeptos de religiões de matriz africana, bem como a destruição de seus espaços sagrados².

Considerando tais aspectos e principalmente, reconhecendo a importância do cinema como espaço de disputa discursiva, é que se propõe analisar as representações da religiosidade afro-brasileira no documentário Orí (Gerber 1989). Precedendo esse exercício analítico, apresenta-se a seguir uma breve contextualização histórica sobre tal universo religioso na cinematografia nacional e sobre tal filme.

\section{Representacõoes ficcionais e documentais das religiões afro}

Nos anos de 1960, com o Cinema Novo, movimento político e estético de crítica ao modelo de grandes estúdios existente no país na época, o cinema passa a ser um espaço de discussão da realidade brasileira, que refletisse as características do Terceiro Mundo. Uma de suas primeiras produções foi Cinco vezes favela (Diegues et al 1962), que a partir de uma visão marxista, apresenta expressões da cultura popular (o futebol, o samba e o candomblé3), como fontes de alienação. Entretanto, nos anos de 1962 e 1963, um conjunto de filmes começa a dar indícios de um novo olhar sobre as expressões culturais e artísticas afro-brasileiras.

Muito embora vários diretores do Cinema Novo inicialmente ignorassem por completo a religião afro-brasileira, ou a vissem como alienada e marginal, algo a ser tolerado ou reformado pelos bem-intencionados esquerdistas seculares, essas atitudes começaram a mudar com a "Renascença Baiana" - a redescoberta cinematográfica das riquezas culturais de Salvador no começo dos anos 1960, um movimento que gerou filmes como Bahia de Todos os Santos (1960), de Trigueirinho Neto; O Pagador de Promessas (1962), de Anselmo Duarte; Barravento (1962), de Glauber Rocha; e A Grande Feira

(1962), de Roberto Pires. (Stam 2008, 297) 
Na década de 1970, com o efetivo fracasso dos ideais revolucionários, a religião popular passa efetivamente a ser vista por outra ótica. O intelectual que outrora se achava na posição de conscientizador do povo se viu de mão atadas diante da censura imposta pelo golpe militar. Esse exercício de autocrítica fez com que alguns cineastas agora passassem a representar a religião sob uma visão bastante favorável.

Na segunda metade dos anos 1960 e, depois, na década de 1970, a representação do povo afirma-se com veio central do cinema e do documentário brasileiro, tornando-se uma de suas temáticas mais produtivas. A abordagem do popular como camada oprimida, explorada e sem direitos, e a valorização de sua cultura como campo para a afirmação social atravessam também os anos 1980. (Ramos 2008, 216)

Essa mudança é evidenciada, segundo Bernardet (1996), na produção documentária de Geraldo Sarno. Em Viramundo, documentário lançado pelo cineasta em 1965, no qual retrata o cotidiano de migrantes nordestinos que chegam a São Paulo, prevalece uma visão do comportamento religioso como resultante de uma situação social alienante e produtora de alienação. Já em laố, lançado em 1976, documentário que registra os ritos de iniciação em um terreiro de candomblé, a religião passa a ser uma forma de preservação de valores tradicionais, a resistência popular contra o avanço do capitalismo e a ditadura militar.

Tal postura de reconhecimento das tradições afro-brasileiras se consolida na década de 1980, quando o documentário "parece acompanhar um movimento também amplo de valorização, nalgumas camadas da sociedade brasileira, da herança africana e das religiosidades afro, que passam a ser vistas como foco de resistência popular, guardiãs de um complexo código cultural" (Mesquita 2006, 34). Isso pode ser constatado primeiramente em laô, de Geraldo Sarno e depois com os documentários Ya-mi Agbá - Mito e metamorfose das mães nagô (Elbein 1979); Dia de Erê (São Paulo 1977); Egungun (Brajsblat 1982); e posteriormente, com Orí (Gerber 1989) e O fio da memória (Coutinho 1991)

Também na ficção e na produção televisiva tal universo religioso ganhou destaque, por exemplo, no filme Pureza Proibida (Sternheim 1974), no qual se tem o protagonismo de Mãe Cotinha (interpretada pela atriz Ruth de Souza), que "pelas relações de afeto e solidariedade que desenvolve com todos, ultrapassa os territórios de pertencimento dos cultos afro" dentro da comunidade de pescadores (Montoro e Ferreira 2014, 153); no longa-metragem A força de Xangô (Cavalcanti 1977), a sambista Dona Ivone Lara interpreta a protagonista, Zulmira de lansã. Baseado no conto laba, de Carybé, esse filme retrata a vingança de Zulmira contra a traição de seu marido, o mulherengo Tonho Tiê, filho de Xangô. Ainda nesse período foi lançada a minissérie Tenda dos Milagres (Grisolli et al 1985), uma adaptação do romance homônimo de Jorge Amado, exibida da Rede Globo.

Atentando-se para "o cinema documentário como um campo no qual emergem novas relações entre alteridade e pluralidade de vozes e sujeitos", como indica Ferreira $(2013,5)$, é que se justifica a seleção de Orí, produção audiovisual que, a partir do ponto de vista de duas mulheres, Raquel Gerber (socióloga e cineasta de origem judia) e Beatriz Nascimento ${ }^{6}$ (historiadora, mulher negra, nordestina e militante) (Figura 1),compreende a religiosidade afro-brasileira como território negro, como quilombo. 
No filme, há vozes femininas e forte abordagem feminista sobre a história, o que aponta para o redirecionamento das questões identitárias, porém de uma perspectiva mais fluida. A espessura conceitual ancorada na ideia de diáspora, a emergência de uma voz feminina e feminista, reverberando o pessoal e o político, e a elaboração formal de Orí traduzem bem a ideia de filme-ensaio e fazem convergir sequências de imagens afirmativas da cultura negra do Brasil nas religiões da umbanda e do candomblé, nos ensaios de escolas de samba, nos desfiles em avenidas e em outros espaços. (Sobrinho 2017, 168)

Durante o período de produção de onze anos, com gravações no Senegal, no Mali e na Costa do Marfim e em três estados brasileiros (São Paulo, Minas Gerais e Alagoas), o filme registra a busca pelas origens africanas, pela identidade negra; também mostra o processo de formação dos movimentos negros nas décadas de 1970/80, as discussões entre vários grupos na luta por visibilidade e inclusão da população negra ainda durante o regime militar. Além disso, o filme acolhe as dimensões subjetivas e afetivas da história pessoal de Beatriz, sua busca por imagem, por identidade, sua experiência de migração.

Como podemos perceber nas suas primeiras sequências, o filme Orí também começa por um questionamento identitário. Mas, ao longo do documentário, outros dados são reunidos para afirmar o caráter híbrido e transatlântico e transcultural dessa identidade diaspórica nascida do encontro de três mundos (África, América e Europa).

O filme adota sucessivamente um tom declamatório, poético, informativo para referir-se à experiência diaspórica. O discurso do filme se torna paulatinamente polifônico: algumas afirmações da narradora em off são completadas por comentários de outros personagens. Além das imagens de África, trechos de outros filmes na estrutura discursiva do documentário complexifica ainda mais a sua dimensão intertextual. Essa polifonia dá uma aparência de "filme de montagem" a Orí. Pela montagem também o filme ostenta seu parti-pris favorável à luta de afirmação do movimento negro. A metade do documentário é consagrada debates, discussões e polêmicas entre militantes do movimento negro (vários trechos da Quinzena do negro na universidade de São Paulo-1977). A partir de lá, Orí assume o compromisso da reconstituição histórica daquilo que podemos chamar da arqueologia do discurso da negritude no Brasil e no mundo. (Bamba 2012, 7)

Desse modo, reconhece-se a vitalidade, o legado crítico e a grandiosidade desse documentário, trabalho mais conhecido e de maior circulação da trajetória intelectual de Beatriz Nascimento (Ratts 2007; Batista 2016), analisado a partir de diferenciadas perspectivas, como a abordagem da problemática diaspórica considerando os aspectos políticos e a reconstituição da história e da memória do Movimento Negro no Brasil (Bamba 2012); a dimensão subjetiva da história e da atuação de Beatriz, que possibilitam analisar tal produção como um documentário performático, classificação proposta pelo teórico Bill Nichols (Ferreira 2013); e ainda o entendimento da atuação de Beatriz Nascimento nos anos de 1980, já como coautora do filme, em um exercício precursor da apropriação que mulheres negras fazem do documentário nas décadas seguintes (Sobrinho 2017).

Em 2009, depois de vinte anos de seu lançamento, Orí foi relançado em formato digital e no ano de 2018 foi exibido na abertura do $22^{\circ}$ Festival do Filme Documentário e Etnográfico (Forumdoc). Deste modo, este trabalho centra-se nas representações da religiosidade afro-brasileira no documentário Orí, a partir de uma investigação aprofundada de sequências, fragmentos fílmicos (Vanoye e Goliot-Lété 1994), que direcionam a análise da construção narrativa e estética de tal filme. 


\section{De Exu à comunidade-terreiro}

Na primeira sequência de Oríno Brasil têm-se cenas de um lugar escuro, com apenas algumas velas acesas, de onde se ouve uma voz grossa; em seguida, vê-se um homem usando uma capa vermelha e um tridente. Fumando um charuto, ele sobe alguns lances de escada a fim de, em outro ambiente, encontrar algumas pessoas, para as quais dá conselhos e reafirma a proteção que lhes oferece; depois se despede abraçando-as e, em cena subsequente, vemos esse homem saindo do transe. Não há legendas, nem a voz do comentário ou a entrevista de um especialista/estudioso para explicar o que está acontecendo. Incorporado em Tata Wndebeoacy (um dos personagens principais do filme), Exu é apresentado de forma direta, sem interlocutores.

Essa reverência a Exu pode ser considerada um indício da representação proposta pelo filme. Como divindade no candomblé, Exu é o responsável pela comunicação entre o mundo dos homens (Aiê) e o mundo dos deuses (Orum), por isso, é o primeiro a ser homenageado nos rituais. Já na umbanda, assume enquanto entidade um aspecto mais próximo dos humanos (Prandi 2010), como uma espécie de compadre a quem se pede socorro para a resolução de todo tipo de problema.

A primeira sequência analisada constitui-se de cenas de elementos do catolicismo e da religiosidade afro-brasileira em um mesmo local, o Ylê Xoroquê, Terreiro de Candomblé, em São Paulo, como indica o letreiro. Essa articulação também é mostrada na imagem e na trilha sonora, pois um padre reza o pai nosso em posição frontal aos atabaques; acompanhada por imagens das pessoas recebendo a hóstia e em seguida dançando em um xirê (estrutura em forma de círculo) e em close, são mostradas no centro, velas e uma oferenda, a narração de Beatriz Nascimento apresenta os grupos ou nações Jeje, Ketu e Angola7, responsáveis pela sobrevivência da cultura africana no Brasil. Segundo ela, o Angola "é talvez o sincretismo brasileiro dessas experiências africanas" (Nascimento 1989).

Tal afirmação indica pontos de diálogo com o argumento de outros autores. Segundo Bastide (1989), diante da condição de escravizados, os africanos tiveram que alterar o significado de suas representações coletivas, como as divindades protetoras da agricultura, que foram colocadas à parte, enquanto deuses guerreiros, como Ogum, Xangô e Exu tomaram lugar de destaque. Tiveram ainda que reinterpretar aspectos semelhantes na religião dos índios, como a capacidade de falar com os mortos e também de entrar em transe; e no Catolicismo, com a devoção aos santos, considerados intermediários entre homem e Deus, que pôde ser adaptada para o culto das divindades africanas (orixás, inquices e voduns), assim como a organização hierárquica das confrarias e ordens religiosas, nas quais os costumes africanos eram aceitos, porém recebiam outro significado. Dessas adaptações forçadas e sujeições saíram as primeiras formas de sincretismo, fenômeno que, de acordo com o autor, não pressupõe uma fusão, mas a coexistência de objetos discordantes.

Também Sodré (1988) defende postura semelhante, pois com base na etimologia da palavra sincretismo, que deriva do grego syn-kerami ou "mistura recíproca entre dois termos distintos", e na característica do processo sincrético que implica sempre em transformações de parte a parte, Sodré defende não ter havido sincretismo entre o catolicismo brasileiro e os cultos negros; ou seja, se mistura, mas sem ter uma real modificação de sua matriz africana. Isso ocorre segundo o autor porque são sistemas simbolicamente incompatíveis, e assim defende que "ao associar algumas de suas divindades, os orixás, com santos da religião católica, os negros não sincretizavam, mas respeitavam (como procediam em relação aos deuses das diversas etnias) e seduziam as diferenças graças à analogia de símbolos e funções" (Sodré 1988, 58). 

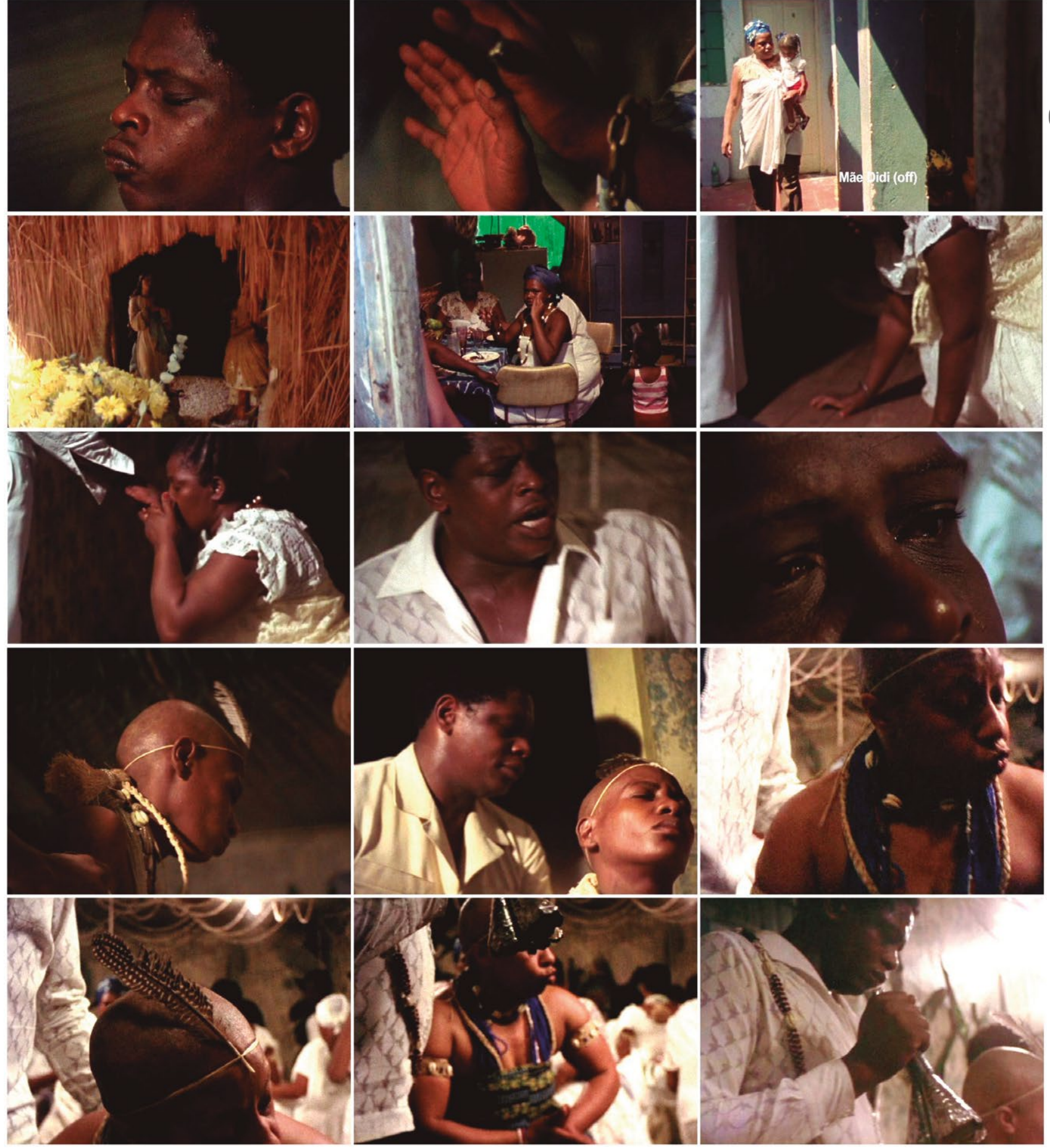

v

v

Figura 2. Religiosidade e identidades negras

Fonte: Orí (Gerber 1989)
Esse exercício de negociação empreendido pelas religiões afro-brasileiras é mostrado na segunda sequência selecionada, tanto numa perspectiva individual quanto coletiva, como pode ser observado na fala (em off) de Mãe Didi (Figura 2), que relata sua origem na nação Jeje, mas para estar mais próxima dos filhos, agora faz parte da Nação Angola; e principalmente, na fala de Tata Wndembeoacy (também em off), que é mostrado em transe e também no exercício da liderança religiosa como sacerdote (sendo referenciado por uma filha-de-santo), e constantemente em planos próximos que destacam seu rosto (Figura 2). Ele ressalta sua identidade negra por meio do nome de seu orixá, em contraponto ao sobrenome do antigo senhor, obrigatório ao escravizado.

“Oswaldo Rodrigues Junior é o nome do senhor, Wndembeoacy é meu nome, Wndembeoacy é África, é negro, agora Rodrigues é o nome do Senhor, que a gente tinha que usar... essa é a diferença" ${ }^{8}$. Tal processo de reconstrução de identidade por meio da religião é referendado na narração de Beatriz Nascimento nas cenas seguintes, nas quais se tem a iniciação de dois filhos-de-santo que, guiados por este sacerdote, também vivenciam um renascimento (Figura 2), no qual orí, a cabeça, se articula com o passado, o presente e o futuro. Isso só é possível 
porque "os orixás ou os voduns ou os inquices (bantos) não são entidades apenas religiosas, mas principalmente suportes simbólicos — isto é, condutores de regras de trocas sociais para a continuidade de um grupo determinado" (Sodré 1988, 55).

Na terceira sequência, o documentário registra a cerimônia conjunta da Festa de Yansã e do Bôrí da Ekedi Sambamijaré de Oxum (Figura 3), destacando os elementos rituais do candomblé, a música, a dança, a indumentária e a linguagem corporal do transe. Além das saudações aos mais velhos, quando a pequena Ekedi coloca-se no chão para referenciar Mãe Didi batendo paó, ou seja, batendo palmas e pedindo-lhe a benção; em seguida a anciã lhe retribui.
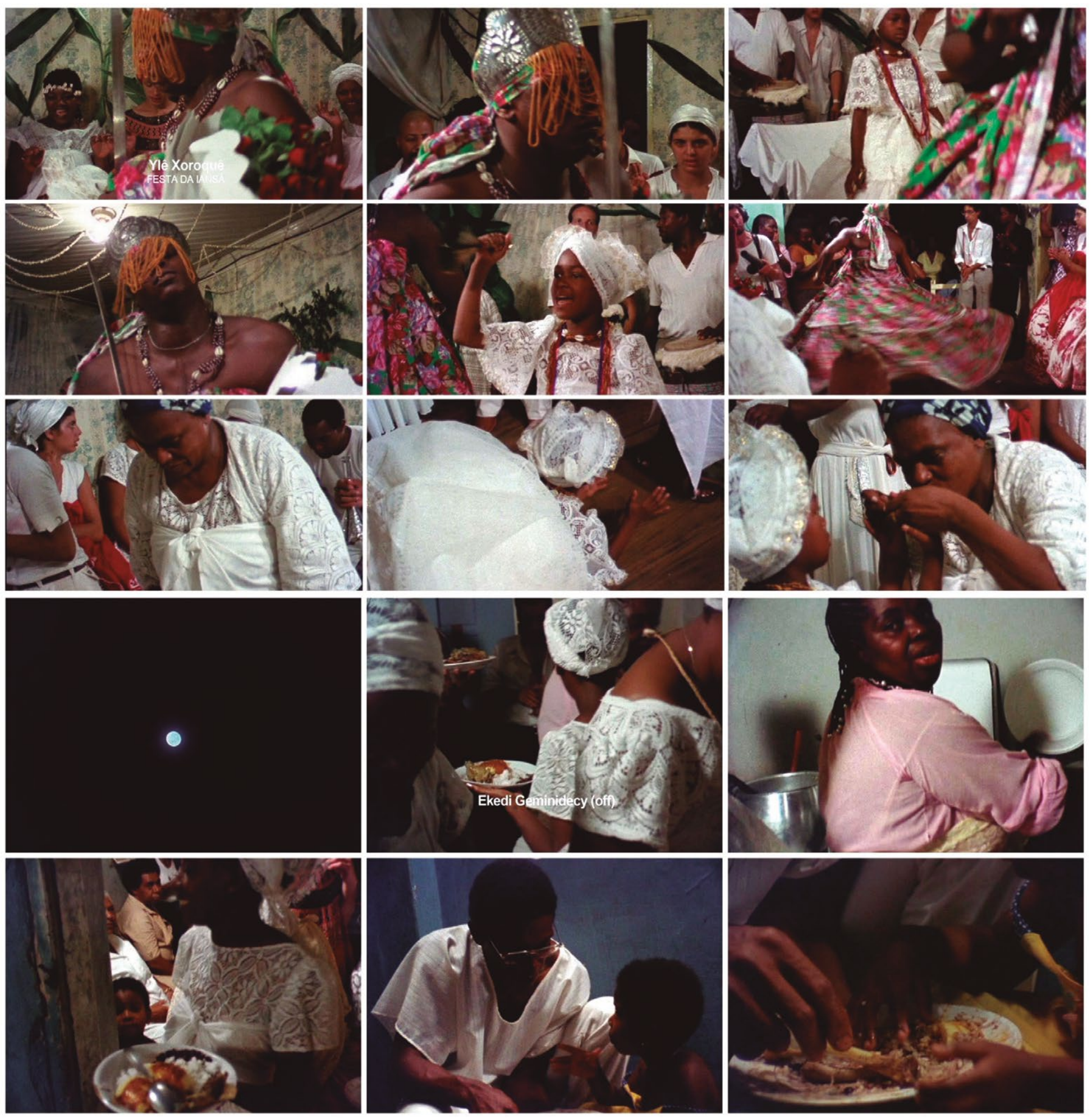
Na narração, Beatriz retoma as nações da religiosidade afro-brasileira como nações místicas; por isso, segundo ela há a necessidade de saudar os orixás, os antepassados, de fazer o borí, rito que significa dar comida à cabeça, considerada um lugar sagrado, a morada do orixá.

A ênfase dada à iniciação como um rito de passagem, indica como este significa o acesso a novos segredos, novas obrigações e nos remete à especificidade das noções de conhecimento, tempo e saber no candomblé, que pressupõe um aprendizado prático, em convívio com os mais velhos na família-de-santo ${ }^{2}$. Após o término da festa, a fala em off da Ekedi Geminidecy (Figura 3) com cenas dela e de outras pessoas na cozinha evidenciam as relações de pertencimento dentro dessa comunidade-terreiro, ao afirmar que:

aqui é as origens dos meus antepassados que a gente vive. Toma banho de ervas, reza-se, você acende as velas, tá muito em contato com os orixás, tá aqui e de repente vira no santo ali e outro aqui, e senta no chão e dorme na esteira, então é isso as minhas raízes, quilombo! (entrevista com Geminidecy 1989)

Tal fala reitera a comunidade-terreiro como um território negro, um espaço de preservação dessa cosmovisão africana e também de reconstituição dos corpos negros, das relações de afeto, da humanidade negada na escravidão. Vale salientar o quanto a comida se faz presente nesses ritos e é evidenciada em planos bem próximos e closes, indicando esse momento de partilha entre as pessoas. Logo, o terreiro de candomblé se configura como "a forma social negro-brasileira por excelência, porque além da diversidade existencial e cultural que engendram, é um lugar originário de força ou potência social para uma etnia que experimenta a cidadania em condições desiguais" (Sodré 1988, 19).

Figura 4. Corpo-memória Fonte: Orí (Gerber 1989)

$\Lambda$

$\Lambda$

\section{Do corpo à terra}

É eloquente a centralidade visual conferida aos corpos negros durante toda a narrativa de Orí, o que pode indicar o desejo de construção de novas visibilidades, novas formas de reconhecimento de homens e mulheres negras em diversas espacialidades. Porém, vale destacar um fragmento do filme no qual a narração de Beatriz, com imagens de um jovem negro dançando em um baile black e de um iaô no ritual de iniciação (Figura 4), afirma que a "linguagem do transe é a linguagem da memória" (Nascimento, 1989).
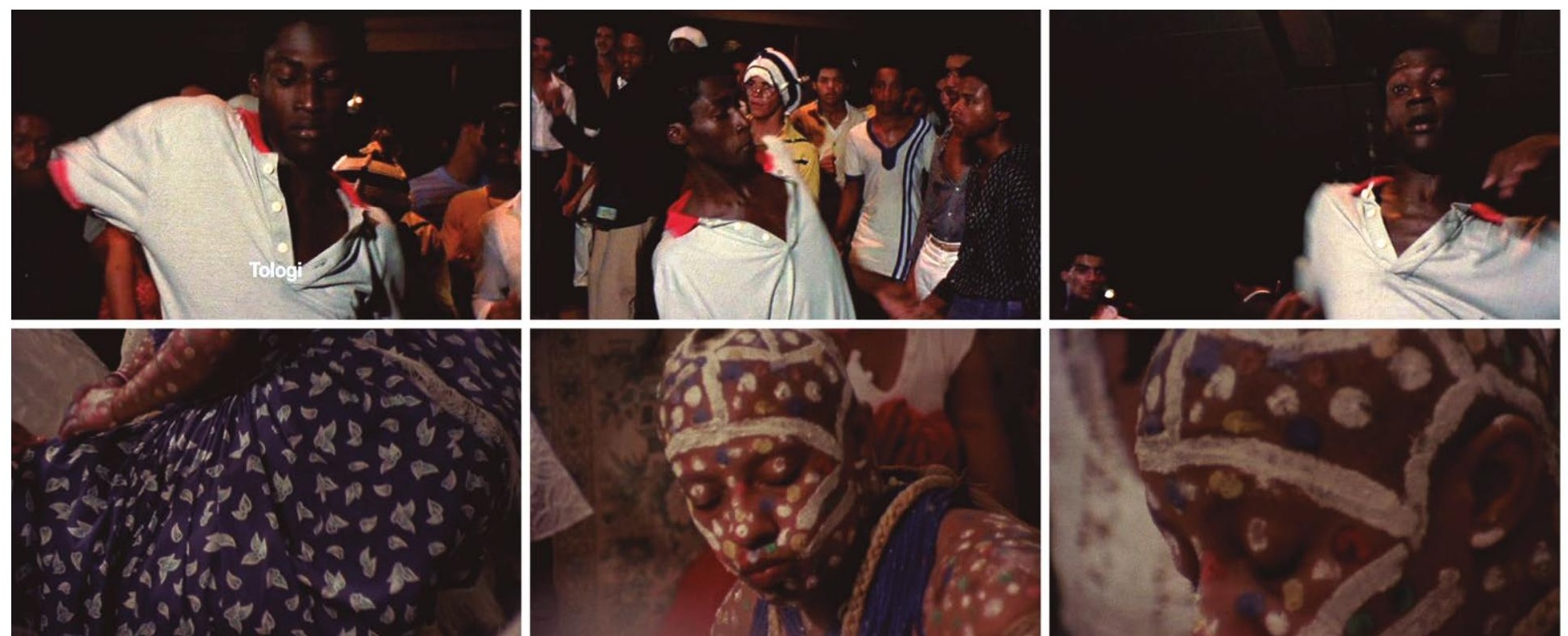
Figura 6. O corpo, a terra e a ancestralidade

Fonte: Orí (Gerber 1989)

\section{$\Lambda$}

$\Lambda$
As imagens e a narração exploram essa prática religiosa em sua capacidade de preservar e ressignificar um modo de vida africano, que privilegia a relação com a natureza, com a terra (destaque para os pés no chão) (Figura 5). Nesse sentido, Oliveira $(2003,99)$ pontua que "é uma forma cultural ecosófica pois não compreende a natureza como um elemento passivo. Ao contrário, ela não reifica a separação binária homem-natureza ou natureza-cultura. O homem é a natureza. Forma com ela um elo indissociável."

Ao assumir a posição de personagem, a narradora compartilha com quem assiste sua experiência pessoal, suas angústias e conflitos e também sua busca por consolo nas divindades do candomblé, que constituem outra sequência analisada. Imagens de um rio, com uma cantiga do orixá Nanã como trilha sonora, a narradora recita um mito ioruba, rogando aos orixás que a alegria se expanda no mundo. Posteriormente, a câmera que percorre o rio (Figura 6), juntamente com a fala em off de Marianno Carneiro da Cunha atestam o caráter sagrado da terra, pois ela é também divindade, é Nanã, é o elemento primordial, o princípio e fim da existência, é "de onde sai o sustento e para onde a vida que de lá saiu volta em forma de mortos, que são cultuados e assim se completa o ciclo" (Nascimento 1989). Em seguida, as imagens do Yao Congonibeoacy de Ogum em transe, com os pés no chão elucidam a fala de Beatriz sobre a relevância da terra nas religiões afro-brasileiras (Figura 6). Segundo ela, "o filho-de-santo quando tem que entrar em um recinto de maior fundamento em um terreiro, ele tem que tá descalço, é pra que a energia seja totalmente captada pelo corpo, a energia dada pela terra" (Nascimento 1989). Ainda sobre essa questão, Beatriz indica a destruição do meio ambiente como um drama para as religiões afro-brasileiras e para toda a humanidade, questão que permanece urgente e atual.

Outras referências às divindades afro-brasileiras estão presentes nos momentos finais do documentário Orí, quando Beatriz afirma idealizar "uma história continente, assim como as paredes de um útero que somente curetando pode-se destruir" (Nascimento 1989). Isso é expresso verbalmente na associação entre a natureza e o útero feminino, e visualmente nas
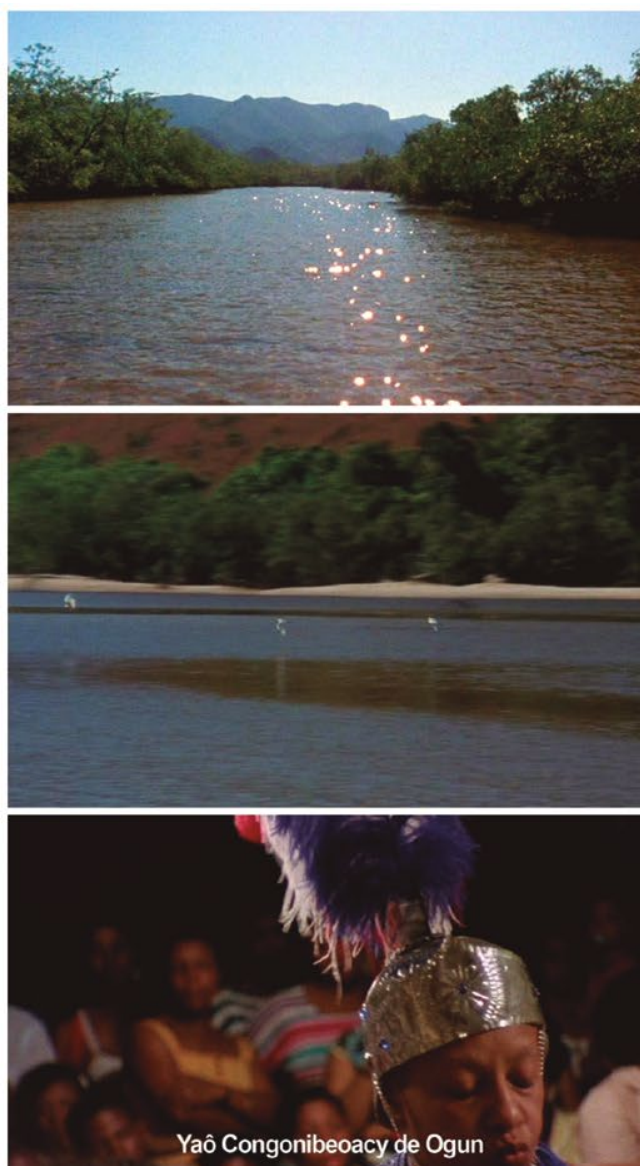

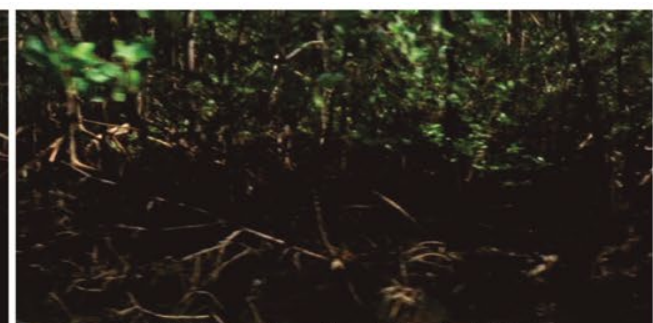

Marianno Carneiro da Cunha (off)
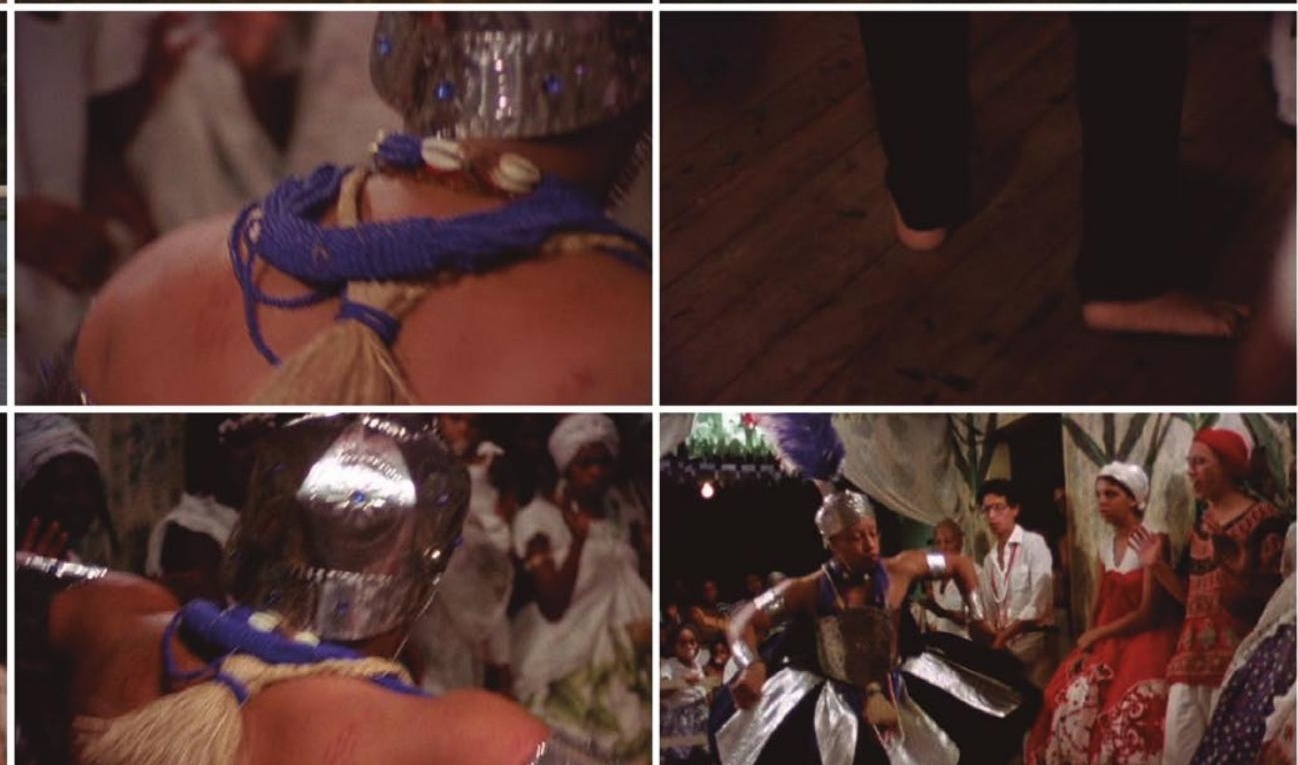
imagens de Oxum (senhora das águas doces, orixá que rege a beleza e a fertilidade), manifestada em uma filha-de-santo e também em águas douradas pelo pôr-do-sol; e ainda quando Abdias do Nascimento, militante e intelectual negro, comenta a participação de Tata Wndembeoacy e outros adeptos do Ylê Xoroquê na abertura do III Congresso de Cultura Negra das Américas, destacando que é o fundamento deste terreiro que fazer a cerimônia inicial de tal evento, também dedicado a Exu, “o deus da contradição dialética, o portador do axé [...], que significa a dinâmica da nossa luta, mas com a integração também desse suporte que é a divindade que desafia o caos cósmico, que é Ogum, o deus da guerra, o restaurador da justiça“ (entrevista com Abdias do Nascimento 1989). Assim, tais divindades guerreiras atuam como suportes simbólicos que alimentam a luta histórica empreendida pelo movimento negro.

\section{Considerações finais}

Por meio do texto poético de Beatriz Nascimento, da pluralidade de vozes das pessoas entrevistadas, do mosaico de imagens de corpos negros em transe e em evidência, das tomadas de palavra, dos gestos corporais, das relações de pertencimento dentro do terreiro, e da ligação com a terra e com a ancestralidade, o documentário Orí constrói representações da religiosidade afro-brasileira como uma filosofia de vida, uma forma social negro-brasileira.

Assim, o repertório mítico dos orixás e a vivência na comunidade do terreiro constituem uma possibilidade de reencontro com os elementos materiais e simbólicos que restituem a humanidade à população negra, por meio de um contínuo renascimento, de uma reencenação da memória, de uma tomada de consciência, que remete às origens africanas, à experiência da escravização e a resistência cotidiana numa sociedade que impõe a homens e mulheres negras a invisibilidade e o silenciamento.

Portanto, constata-se neste documentário um deslocamento na forma de representar a religiosidade afro-brasileira no cinema. Isso se deve pela maneira como Beatriz Nascimento e Raquel Gerber se apropriam da linguagem cinematográfica para representar o encontro, a proximidade, a vivência pessoal dentro desse universo religioso, compartilhando entre si a autoria, a construção dessa tessitura fílmica complexa, subjetiva, performática; e compartilham com quem assiste, uma visão de mundo africana, que compreende o corpo como espaço do sagrado e a religião como indissociável da vida cotidiana. 
NOTAS

1. De acordo com o autor, tal discussão foi realizada na mesa-redonda "Os terreiros, as imagens", no VI Colóquio Cinema, Estética e Política, realizado em setembro de 2017, no Recôncavo baiano e contou ainda com a participação de Mãe Mari (do Ilê Axé Pakolè, de Cachoeira), Makota Kidoiale (do quilombo Manzo Ngunzo Kaiango, em Belo Horizonte), Pai Idelson (do llê Axé Ogunjá, de Cachoeira) e do ogã Tata Marcelino (do Zogodô Malé Daho Taby, em Cachoeira).

2. Sobre o aumento do número de denúncias de violência contra religiões afrobrasileiras, ver Portal Aprendiz UOL (2019) e Portal G1 (2019).

3. Religião brasileira de matriz africana que se constituiu na Bahia no século XIX e na qual se cultuam os orixás e outras divindades africanas; também é conhecida pelas denominações regionais de xangô, em Pernambuco, tamborde-mina, no Maranhão, e batuque, no Rio Grande do Sul (Prandi 2004).

4. laô ou Yaô é uma palavra de origem ioruba que significa "filho/a-de-santo", ou seja, a pessoa que é iniciada na religião e incorpora os orixás por meio do transe.

5. Nos anos de 1990, a abertura de canais de televisão a cabo, alguns apoios estatais para a produção documentária, e também o surgimento de diversos festivais dedicados ao gênero, como a Mostra Internacional do Filme Etnográfico (1993, no Rio de Janeiro), Festival é Tudo Verdade (1996, Rio de Janeiro e São Paulo) e o Festival do Cinema Documentário e Etnográfico de Belo Horizonte (1996) compuseram um novo impulso dado ao documentário brasileiro, no qual permanece 0 destaque a religiosidade na produção documental brasileira, ressalta Monte-Mór (2004).

6. Beatriz Nascimento nasceu em Sergipe, em 1942, e aos sete anos migrou com a família para o Rio de Janeiro, onde se formou em História pela Universidade Federal do Rio de Janeiro (UFRJ). Participou de um grupo de ativistas negras/ os que posteriormente formariam o Grupo de Trabalho André Rebouças, na Universidade Federal Fluminense (UFF), onde continuou sua carreira acadêmica com o curso de pós-graduação no qual desenvolveu o projeto "Sistemas alternativos organizados pelos negros dos quilombos às favelas". Também é autora de vários artigos sobre racismo, quilombos e cultura negra; além de ter promovido e participado de cursos, conferências, palestras e simpósios no Brasil e no exterior. Em janeiro de 1995, período em que era mestranda em Comunicação Social na UFRJ, sob a orientação do professor Muniz Sodré, Beatriz Nascimento foi assassinada ao defender uma amiga de seu companheiro violento, deixando uma filha (Bethânia Gomes) (Ratts 2007).

7. Segundo Prandi (1995), a nação ketu, na qual predominam os orixás, a língua e os ritos de iniciação de origem iorubá mantém-se como uma referência de religiosidade de matriz africana, visto sua influência sobre as outras nações; a nação angola, originária dos povos de língua banto, adotou o panteão dos orixás iorubás, embora com os nomes de seus inquices, que dividem espaço com o culto dos caboclos; e a nação jeje, que se subdivide em jeje-mahin, do estado da Bahia, e a jeje-mina, do Maranhão derivaram suas tradições e língua ritual dos povos ewê-fon, e tem como divindades os voduns e os encantados (espíritos de humanos que teriam vivido em outras épocas e outros países). 
8. Entrevista em Orí (Gerber 1989).

9. A família-de-santo é a comunidade de culto ao candomblé, que tem a liderança espiritual de um sacerdote ou sacerdotisa, chamados de lalorixá ou Babalorixá (mãe-de-santo ou pai-de-santo), os ogãs e equedes (integrantes em cargos de confiança), os/as Ebomis (filhas/os-de-santo com mais de sete anos de iniciação) e os/as laôs (filhos/as-de-santo, ou seja, iniciadas na religião, que incorporam os orixás por meio do transe).

10. Ebó significa sacrifício realizado por meio da entrega de oferendas (que podem ser folhas, frutas, velas, alimentos secos e bebidas) às divindades, para atender alguma finalidade, como limpeza espiritual e/ou resolução de problemas. 
[REFERENCIAS]

Araújo, Joel Z. 2000. "Identidade racial e estereótipos sobre o negro na TV brasileira." Em Tirando a máscara ensaios sobre o racismo no Brasil, editado por Antônio Sérgio Guimarães e Lynn Huntley, 77-96. São Paulo: Paz e Terra.

Bamba, Mahomed B. 2012. "Os modos de figuração da memória e das experiências diaspóricas em quatro documentários brasileiros." Nuevo Mundo-Mundos Nuevos: 1-13. https://journals. openedition.org/nuevomundo/62679

Bernardet, Jean-Claude. 1996. Brasil em tempo de cinema: ensaio sobre o cinema brasileiro. Rio de Janeiro: Paz e Terra.

Bastide, Roger. 1989. As religiões africanas no Brasil: contribuição a uma Sociologia das interpenetrações de civilizações. Tradução por Maria Eloisa Carvalho e Olívia Krähenbühl. $3^{\mathrm{a}}$ edição. São Paulo: Livraria Pioneira Editora.

Batista, Wagner V. 2016. "Palavras sobre uma historiadora transatlântica: estudo da trajetória intelectual de Maria Beatriz Nascimento." Tese de doutorado da Universidade Federal da Bahia.

Brajsblat, Carlos, dir 1981. Egungun. Rio de Janeiro, Brasil: SECNEB/ Embrafilme.

Carrança, Flávio, e Rosane Borges. 2004. Espelho infiel: o negro no jornalismo brasileiro. São Paulo: Imprensa Oficial do Estado de São Paulo.

Cavalcanti, Iberê, dir. 1977. A força de Xangô. Rio de Janeiro, Brasil: Cine TV Áudio Visual.

Coutinho, Eduardo, dir. 1991. O fio da memória. Rio de Janeiro, Brasil Cinefilmes/FUNARJ.

Diegues, Cacá, Leon Hirszman, Joaquim Pedro de Andrade, Miguel Borges e Marcos Farias. 1962. Cinco vezes favela. Rio de Janeiro, Brasil: Centro Popular de Cultura da União Nacional dos Estudantes/Saga Filmes.

Elbein dos Santos, Juana, dir. 1979. Ya-mi Agbá - Mito e metamorfoses das mães nagô. Rio de Janeiro, Brasil: SECNEB/Embrafilme.

Ferreira, Ceiça. 2013. "Uma representação de si para o mundo: afetos e subjetividades no documentário performático." Razón y Palabra 18(83). http://www.razonypalabra.org.mx/N/N82/V82/12_Ferreira_V82.pdf

Geminidecy, Ekedi. 1989. [entrevista]. Em: ORÍ. 1989. Dirigida por Raquel Gerber. Brasil: Angra Filmes.

Gerber, Raquel, dir. 1989. ORÍ. Brasil: Angra Filmes.

Grisolli, Paulo A., Maurício Farias e Ignácio Coqueiro, dir. 1985. Tenda dos milagres. Rio de Janeiro, Brasil: Rede Globo.

Guimaraes, César. 2019. Filmar os terreiros, ontem e hoje. Perspectivas em Ciência da Informação Horizonte 24: 23-36. http://www.scielo.br/ pdf/pci/v24nspe/1413-9936-pci-24-spe-23.pdf

Hall, Stuart. 2010. "El espectáculo del 'Otro'". Em Sin garantías: trayectorias y problemáticas en estudios culturales, editado por Eduardo Restrepo, Catherine Walsh, e Víctor Vich, 419-446. Bogotá: Envión Editores.
1997 "The centrality of culture: Notes on the cultural revolutions of our time" [A centralidade da cultura: notas sobre as revoluções culturais do nosso tempo]. Em Media and Cultural Regulation, editado por Kenneth Thompson, 207-38. Londres: Sage.

JornalGazetadoPovo.2019, janeiro30. “Recordécondenadaaexibirprogramas sobre religiões de matriz africana". https://www.gazetadopovo.com. br/justica/record-e-condenada-a-exibir-programas-sobre-religioesde-matriz-africana-4va0sslbzxyuwr3n4dm2pkpud/.

Luz, Rogério. 2002. Filme e subjetividade. Rio de Janeiro: Contra capa.

Mesquita, Cláudia C. 2006. "'Deus está no particular' - Representações da experiência religiosa em dois documentários brasileiros contemporâneos." Tese de Doutorado em Ciências da Comunicação, Escola de Comunicações e Artes, Universidade de São Paulo.

Monte-Mór, Patrícia. 2004. "Religião e filmes documentários no Brasil." Revista Religião e Sociedade 24(2): 61-72.

Montoro, Tania, e Ceiça Ferreira. 2014. "Mulheres negras, religiosidades e protagonismos no cinema brasileiro." Galaxia 27: 145-159. http:// www.scielo.br/pdf/gal/v14n27/12.pdf.

Nascimento, Beatriz. 1989. [narração]. Em: ORÍ. 1989. Dirigida por Raquel Gerber. Rio de Janeiro, Brasil: Angra Filmes.

Oliveira, David E. 2003. Cosmovisão africana no Brasil: elementos para uma filosofia afrodescendente. Fortaleza: LCR.

Portal Aprendiz UOL. 2019, julho 17. “Terreiros são alvo de intolerância religiosa e racismo no Brasil." https://portal.aprendiz.uol.com.br/2019/07/17/ terreiros-sao-alvo-de-intolerancia-religiosa-e-racismo-brasil/

Prandi, Reginaldo. 2010. "Coração de Pombagira." Esboços: histórias em contextos globais, Florianópolis 17(23): 141-150. https://periodicos.ufsc. br/index.php/esbocos/article/view/2175-7976.2010v17n23p141/17584.

2004. "0 Brasil com axé: candomblé e umbanda no mercado religioso." Estudos Avançados 18 (52), 223-238. http://www.revistas. usp.br/eav/article/view/10033.

1995. "As religiões negras do Brasil: para uma sociologia dos cultos afro-brasileiros." Revista da USP28, 64-83. http://www.usp.br/ revistausp/28/05-prandi.pdf.

Sternheim, Alfredo, dir. 1974. Pureza Proibida. Rio de Janeiro, Brasil: R. G. Produções Cinematográficas.

Ramos, Fernão P. 2008. Mas afinal... o que é mesmo documentário? São Paulo: Editora Senac.

Ratts, Alex. 2007. Eu sou atlântica: sobre a trajetória de vida de Beatriz Nascimento. São Paulo: Imprensa Oficial de São Paulo.

São Paulo, Olney, dir. 1977. Dia de Erê. Rio de Janeiro, Brasil: Pilar Filmes Ltda.

Sarno, Geraldo, dir. 1965. Viramundo. Rio de Janeiro, Brasil: Thomas Farkas

Sarno, Geraldo, dir. 1976. laô. Rio de Janeiro, Brasil: Saruê Filmes; Mariana Filmes. 
Sodré, Muniz.1999. Claros e Escuros:Identidade, povo e mídia no Brasil. 2. ed.Petrópolis, RJ: Vozes.

Stam, Robert. 2008. Multiculturalismo tropical: uma história comparativa da raça na cultura e no cinema brasileiros. Tradução de Fernando S. Vugman. São Paulo: Edusp.

Silva, Conceição de M. F. 2016. "Mulheres negras e (in)visibilidade: imaginários sobre a intersecção de raça e gênero no cinema brasileiro (1999-2009)." Tese de Doutorado em Comunicação, Faculdade de Comunicação, Universidade de Brasília.

2010. "Barravento, Orí e Santo Forte: representação das religiões afro-brasileiras no cinema." Dissertação de Mestrado em Comunicação Social, Faculdade de Comunicação e Biblioteconomia, Universidade Federal de Goiás.

Sobrinho, Gilberto A. 2017. "Identidade, resistência e poder: mulheres negras e a realização de documentários." Em Feminino e plural: mulheres no cinema brasileiro, editado por Karla Holanda eMarina Cavalcanti Tedesco, 163-174. Campinas: Papirus.

Sodré, Muniz. 1988. O terreiro e a cidade: a forma social negrobrasileira. Petrópolis: Vozes.

Portal G1. 2019, junho 9. "Traficantes espalham o ódio contra religiões afro-brasileiras pelo país." https://g1.globo.com/fantastico/ noticia/2019/06/09/ traficantes-espalham-o-odio-contrareligioes-afro-brasileiras-pelo-pais.ghtml.

Vanoye, François e Anne Goliot-Lété. 1994. Ensaio sobre a análise fílmica. Tradução de Marina Appenzeller. Campinas: Papirus. 